\title{
Lusioersily
}

\section{Characterization of hollow cathode and parallel plate microplasmas: scaling and breakdown}

Greenan, J., Mahony, CMO., Mariotti, D., \& Maguire, PD. (2011). Characterization of hollow cathode and parallel plate microplasmas: scaling and breakdown. Plasma Sources Science and Technology, 20(2), 025011. http://stacks.iop.org/0963-0252/20/i=2/a=025011

Link to publication record in Ulster University Research Portal

\section{Published in:}

Plasma Sources Science and Technology

Publication Status:

Published (in print/issue): 23/03/2011

\section{Document Version}

Publisher's PDF, also known as Version of record

\section{General rights}

Copyright for the publications made accessible via Ulster University's Research Portal is retained by the author(s) and / or other copyright owners and it is a condition of accessing these publications that users recognise and abide by the legal requirements associated with these rights.

\section{Take down policy}

The Research Portal is Ulster University's institutional repository that provides access to Ulster's research outputs. Every effort has been made to ensure that content in the Research Portal does not infringe any person's rights, or applicable UK laws. If you discover content in the Research Portal that you believe breaches copyright or violates any law, please contact pure-support@ulster.ac.uk. 
Characterization of hollow cathode and parallel plate microplasmas: scaling and breakdown

This article has been downloaded from IOPscience. Please scroll down to see the full text article.

2011 Plasma Sources Sci. Technol. 20025011

(http://iopscience.iop.org/0963-0252/20/2/025011)

View the table of contents for this issue, or go to the journal homepage for more

Download details:

IP Address: 193.61.144.108

The article was downloaded on 25/03/2011 at 10:39

Please note that terms and conditions apply. 


\title{
Characterization of hollow cathode and parallel plate microplasmas: scaling and breakdown
}

\author{
J Greenan, C M O Mahony, D Mariotti and P D Maguire \\ Nanotechnology and Integrated Bio-Engineering Centre, University of Ulster, Newtownabbey, \\ BT37 0QB, UK \\ E-mail: pd.maguire@ulster.ac.uk
}

Received 27 September 2010, in final form 12 January 2011

Published 23 March 2011

Online at stacks.iop.org/PSST/20/025011

\begin{abstract}
We present an experimental comparison of parallel plate and hollow cathode microplasma structures, operated at high pressure with narrow anode-cathode gaps. A moveable anode arrangement with $\pm 12 \mu \mathrm{m}$ spatial resolution was used to vary the electrode separation to cover the $p d$ range between 0.01 and 4 Torr $\mathrm{cm}$ for both structures. The hollow cathode discharge was operated with pressure-diameter $(p D)$ product values between 1.8 and 7.2 Torr $\mathrm{cm}$ and an aspect ratio of $\sim 5$. Analysis of $V-I$ characteristics shows $j / p^{2}$ and $j^{2} p$ scaling for low and high current modes, respectively. Electron temperature estimates between 2 and $3 \mathrm{eV}$ were obtained by solving a numerical collisional-radiative model based on transitions from $4 p$ argon levels. The hollow cathode sheath thickness for both ionizing and non-ionizing sheath conditions was determined analytically and the diffusion equation was solved numerically to estimate the plasma density profile for the ionizing sheath case.
\end{abstract}

(Some figures in this article are in colour only in the electronic version)

\section{Introduction}

Microscale plasmas have an electrode configuration with at least one critical dimension below one millimetre [1]. By spatially confining plasma sources to these reduced dimensions, stable, non-thermal equilibrium high pressure discharges are possible in a range of gases [2,3]. Their properties differ considerably from other high pressure sources leading to heightened interest for applications in, e.g., plasma displays, VUV spectroscopy, atmospheric pressure materials processing [4], localized surface modification and maskless etching, gas treatment, analytical chemistry, sterilization and decontamination, detoxification, efficient light sources [5, 6] and biomedical applications [2,7-10]. We are interested in the biomedical potential of microplasmas for biocompatible 3D coatings, breath sensors, nanoparticles for point-of-care diagnostics and drug delivery [11-13].

Much of the detailed investigative work is based on dc driven microhollow cathode (MHC) structures [1, 14], mainly due to their interesting properties, potential applications and ease of fabrication. Schoenbach et al [15] obtained stable MHC discharge operation at atmospheric pressure while device diameters have been scaled from $\sim 400 \mu \mathrm{m}$ [16-18] down to $30 \mu \mathrm{m}$ [19]. At these dimensions, very high intensity sources have been obtained with estimated electron densities of the order of $10^{15} \mathrm{~cm}^{-3}[3,20-24]$ and increases in $n_{\mathrm{e}}$ with plasma confinement [25], pressure [20] and temperature [21]. Electron temperatures for large scale $(\sim 1 \mathrm{~cm})$ hollow cathode discharges vary from 2 to $5 \mathrm{eV}$, while for MHC discharges, measured $T_{\mathrm{e}}(\mathrm{Ar})$ ranged from 0.6 to $1 \mathrm{eV}[24,26]$ with typical gas temperatures, $T_{\mathrm{g}}$, from room temperature to $2000 \mathrm{~K}$ [9]. At such dimensions, accurate measurements are extremely challenging and this is exacerbated as dimensions are reduced further. Rudimentary scaling model predictions [7] offer the possibility of extremely high electron densities as the diameter is scaled to around $1 \mu \mathrm{m}$, although existing models of microplasmas are not sufficiently mature to verify this.

While understanding of these devices has grown, there is still a significant gap in our knowledge of underlying principles, not least due to the challenges of diagnostics and simulation at very small dimensions. Scaling and spatial confinement of discharge dimensions is likely to result in new physical behaviour and there is a need to establish an understanding of the physics that govern and control the 
behaviour of these discharges [10]. As dimensions are reduced, a transition from a plasma with bulk properties to a dimension-dependent plasma will occur, with the likely dominating factors being surface-to-volume ratio and the electrode spacing which impact on energy balance, stability and electric field distributions. This is defined by Mariotti and Sankaran [27] as the microplasma regime and they suggest a simple relationship $\left(\Lambda / T_{\text {gas }}^{0.75} \propto\left(p n_{\mathrm{e}}\right)^{-1 / 2}\right)$ between plasma dimension $(\Lambda)$, density and pressure where non-thermal equilibrium $\left(T_{\text {gas }} \ll T_{\mathrm{e}}\right)$ is maintained. Also, if the plasma size is similar to the Debye length, quasineutrality may not be preserved. For typical microplasma conditions this may occur in the 10-100 $\mu \mathrm{m}$ size regime and sustainment must involve additional mechanisms compared with macroscale plasmas.

The scaling of macrosized parallel-plate (PP) devices has been studied over many decades and is well understood. Paschen scaling of breakdown voltage depends on $E / N$ and $p d$, where $N$ is gas density and $d$ is the electrode gap. Phelps [28] also describes a voltage scaling with $j / p^{2}$ (or the equivalent $j d^{2}$ ). Deviations from Paschen behaviour have been observed and are thought to originate from high cathode fields and their impact on secondary electron or field emission of electrons $[13,29,30]$. Charge neutrality and discharge structure are relatively unchanged down to gaps of $\sim 100 \mu \mathrm{m}[31,32]$. We have investigated the dc breakdown and current characteristics of various PP structures and have tested $p d$ and $j / p^{2}$ scaling for gaps of a few millimetres down to $20 \mu \mathrm{m}[12,13,33]$. Low pressure conventional hollow cathodes ( $\mathrm{CHCs}$ ) have a complicated dependence on various discharge parameters and have been extensively studied [34-36]. Analysis by Kolobov and Tsendin [35] concluded that exponential electron multiplication within large sheath regions was responsible for the hollow cathode effect (HCE) whereas a model by Arslanbekov et al [37] indicates pendular electron motion (electrostatic trapping) and linear electron multiplication in the plasma bulk leads to very thin cathode sheaths and HCE. CHC devices have received little experimental attention, however, with regard to pressure or dimension scaling. Additional dimensions need to be considered, namely hollow cathode diameter $(D)$, hollow cathode length $(L)$ and sheath width within the hollow $(s)$. Here $s / D$ is expected to remain constant as $D$ is reduced and current density $(j)$ scales with $s^{-2.5}$. Marić et al [38] and Li et al [39] have recently measured CHC $V-I$ characteristics at high pressure while imaging the glow to determine operational modes while high pressure MHC characteristics have been modelled by Kushner [40] and Kim et al [24].

Standard microhollow devices based on metal-dielectricmetal (MDM) structures are not very suitable for investigating scaling relationships due mainly to fabrication constraints. In particular, achieving dielectric quality and thickness, which determines the gap, can be problematic and the breakdown initiation dependence on edge fields at the anode-dielectric interface is highly susceptible to localized micro-features [9]. We have therefore opted for a separate moveable anode with a range of $1 \mathrm{~mm}$. High resolution $( \pm 12 \mu \mathrm{m})$ control of the anode allows detailed investigation of $p d$ scaling by varying the gap down to $<10 \mu \mathrm{m}$ as well pressure, allowing for the first time a detailed comparison. This arrangement also enables a similar measurement on micro-PP devices. We wish to avoid lifetime issues observed with ultra-small diameter dc devices and also consider a relatively high aspect ratio cathode $(L / D>5)$. Etching of symmetrical cavities to this ratio has proven difficult and hence we have opted for narrow metal tubing with a fixed diameter of $\sim 2 \mathrm{~mm}$ and length $10 \mathrm{~mm}$. Thin wall tubes were used and hence plasma expansion outside the tube, with associated self-pulsing [41] is limited.

\section{Experimental}

The plasma devices are housed in a $(0.28 \mathrm{~m}$ diameter, $0.36 \mathrm{~m}$ long) cylindrical vacuum chamber. Pumping is via a standard rotary pump and gas pressure control is achieved using a combination of needle and throttle valves. Two plasma source electrode configurations were fabricated for this study: PP and hollow cathode. All device components (e.g. electrodes, insulating supports) were engineered by high precision machining processes to ensure axial linearity and parallelism of electrodes and electrode surfaces. Incorporated in these plasma source devices is a standalone high resolution $(1 \mu \mathrm{m})$ linear motion actuator with overall positional accuracy of $\pm 12 \mu \mathrm{m}$, which enables precise remote control of the anode position and thus gap $(d)$, and is particularly valuable in $p d$ scaling measurements.

\subsection{Parallel plate (setup A)}

The PP device (figure 1) has an electrode configuration that consists of a solid stainless steel anode rod and a solid cylindrical stainless steel cathode, both of diameter $D=3 \mathrm{~mm}$. To reduce long path breakdown effects, the curved outer face of the anode has an insulated thin film coating and the cathode is housed in an insulating support.

\subsection{Hollow cathode (Setup B)}

The MHC device (figure 2) consists of the same insulated stainless steel anode as the PP device, with the cathode replaced by a stainless steel hollow cathode $(\mathrm{OD}=2.6 \mathrm{~mm}$, ID $=$ $1.8 \mathrm{~mm}, L=10 \mathrm{~mm}$ ). Zero positioning of the electrodes is achieved by moving the anode in $5 \mu \mathrm{m}$ steps towards the cathode until electrical contact is made.

The external electrical circuit, figure 3, consists of a dc high voltage power supply in series with a ballast resistor, the discharge device and measurement resistor. High voltage probes for current and voltage measurement are connected to a digital storage oscilloscope (DSO).

Optical emission spectroscopy is obtained via fibre optics (shown as 'FO A' in figure 1 and as 'FO B' in figure 2) connected to an Ocean Optics UV-VIS HR-4000 spectrometer (resolution $0.28 \mathrm{~nm}$ ). FO A samples radial emission from the anode-cathode gap and is mounted on an XY manipulator which can be adjusted from outside vacuum to maximize the OES signal. FO B is fixed at the rear face of the hollow cathode, capturing axial plasma emission from both the interior volume of the tube and the anode-cathode gap region. 


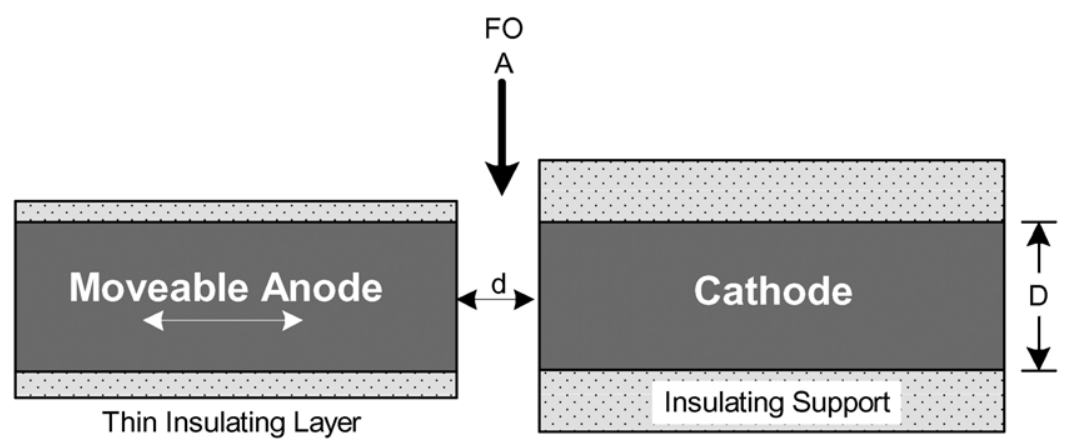

Figure 1. Cross-sectional schematic of the PP device.

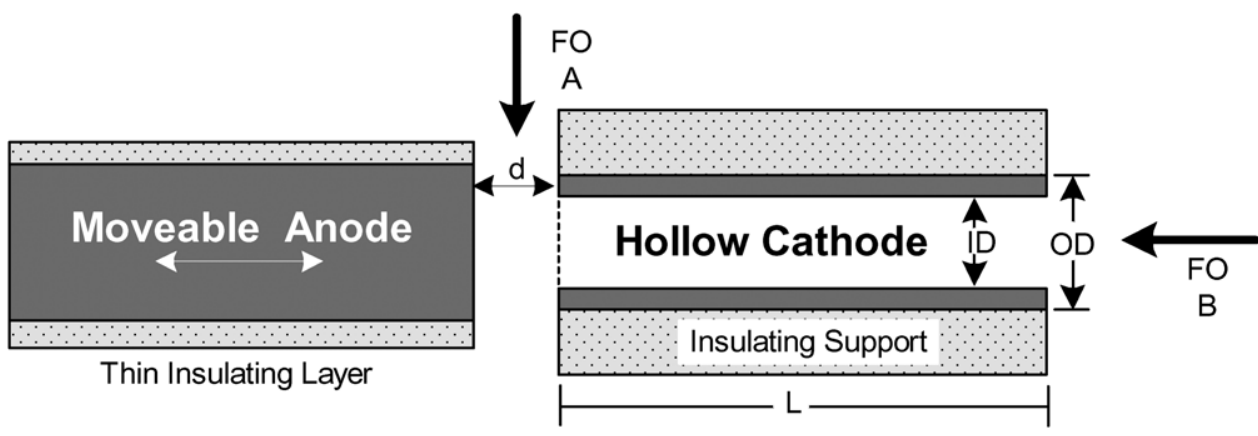

Figure 2. Cross-sectional schematic of the hollow cathode plasma source.

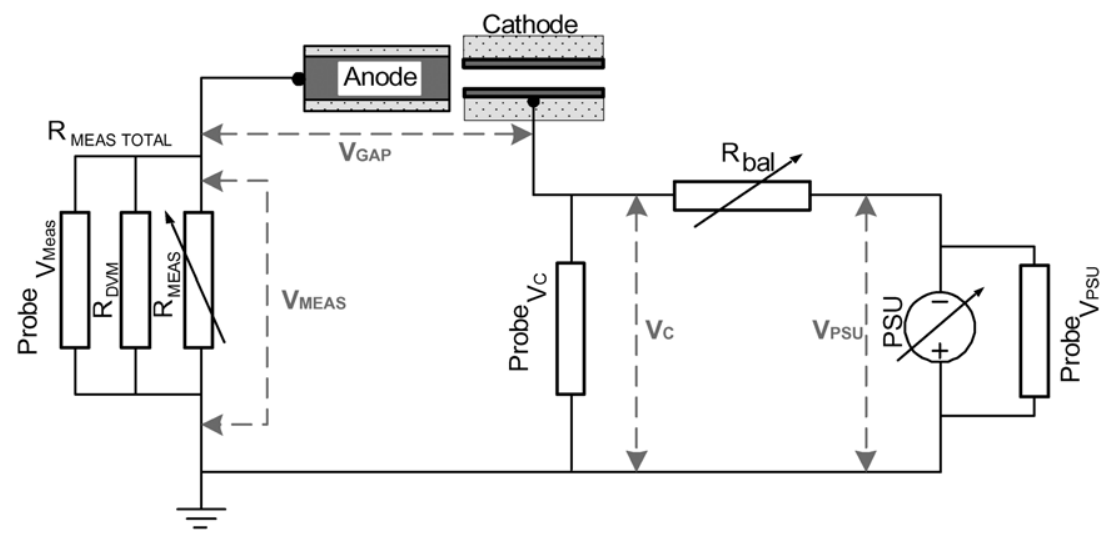

Figure 3. Electrical measurement setup for setup A and setup B.

\subsection{Experimental procedure}

All measurements were performed in pure argon gas. Before any measurements were obtained, an electrode conditioning process was undertaken to improve reliability and repeatability. This process consisted of running a stable low current $(\sim 7 \mu \mathrm{A})$ argon discharge at a pressure of $\sim 10$ Torr and a gap $d=500 \mu \mathrm{m}$ until current and voltage stabilized to preestablished standard levels, typically for $2 \mathrm{~h}$. The vacuum chamber was then pumped down to $\sim 0.1$ Torr, refilled with argon and the discharge run again for about $20 \mathrm{~min}$ until the pre-established standard $V-I$ characteristics were again obtained. The experimental phase then commenced after commissioning. Electrical and optical characteristics of discharges for a range of gaps $(10 \mu \mathrm{m}<d<1 \mathrm{~mm})$ and pressures (10 Torr $<p<40$ Torr) were recorded. The desired gap $(d)$ and pressure were first set, and then electrical measurements were obtained by manually sweeping $V_{\mathrm{PSU}}$ between $0 \mathrm{~V}$ and $1 \mathrm{kV}$. The DSO was used to record the cathode voltage, $V_{\mathrm{C}}$, using Probe $V_{V_{\mathrm{C}}}$ and the potential, $V_{\text {MEAS }}$, across the $9.997 \mathrm{k} \Omega$ current measurement resistor, $R_{\text {MEAS }}$, using Probe ${ }_{V_{\mathrm{MEAS}}} . V_{\mathrm{PSU}}$ was also monitored on the DSO. For low current measurements $(I<8 \mu \mathrm{A})$ a ballast resistor value of $R_{\mathrm{bal}}=1 \mathrm{M} \Omega$ was set while for $I>450 \mu \mathrm{A}$, $R_{\text {bal }}=100 \mathrm{k} \Omega$. Visible spectra of higher current discharges $(1 \mathrm{~mA}<I<3.5 \mathrm{~mA})$ were recorded and the position of fibre optic FO A was adjusted to maximize the signal at each value of $d$.

\section{Results}

The typical $V-I$ characteristics (figure 4) obtained from the above electrical study provides data on discharge turn-on/off 


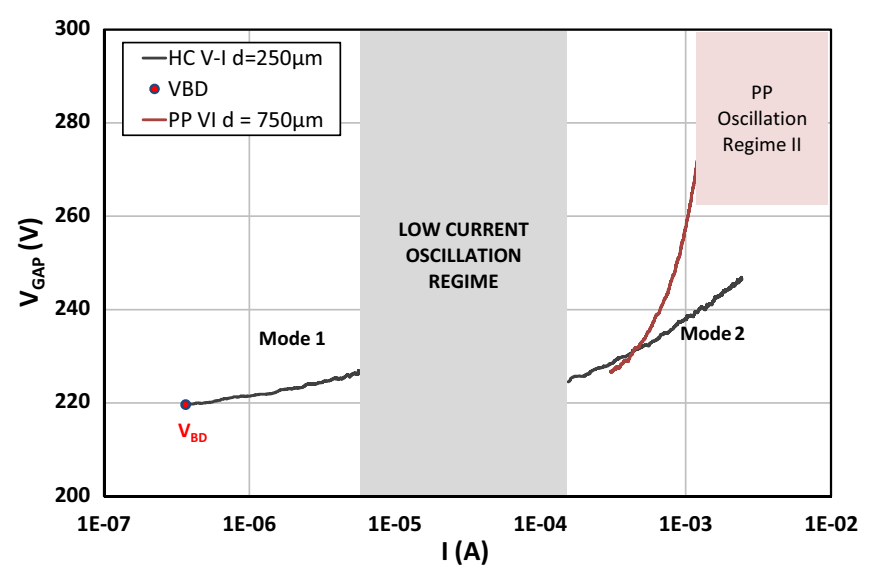

Figure 4. $V-I$ characteristics demonstrating the modes of operation and $V_{\mathrm{BD}}$ for a hollow cathode and PP devices.

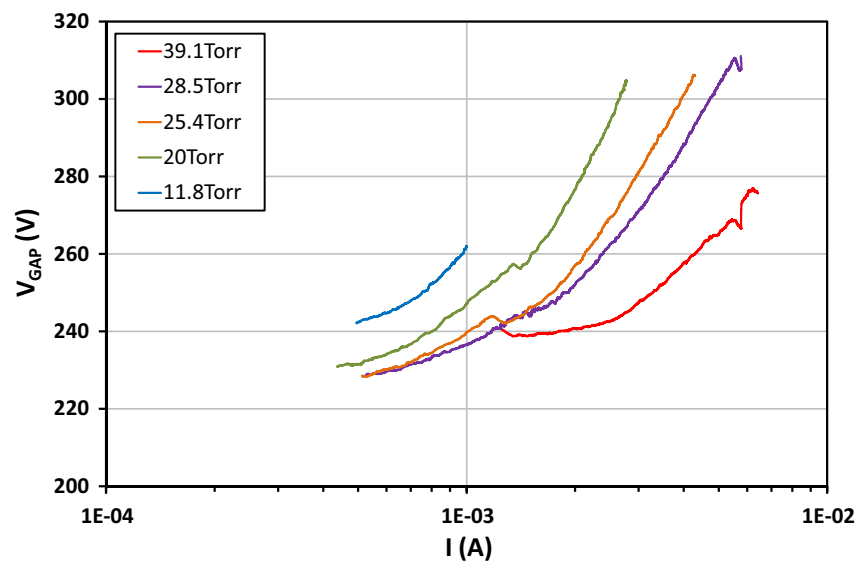

Figure 5. $V-I$ characteristics of mode 2 for a PP device where $d=500 \mu \mathrm{m}$.

behaviour and several operation modes. For the PP, only a stable higher current discharge $(500 \mu \mathrm{A}<I<\sim 1.5 \mathrm{~mA})$ was observed. Oscillation regimes are present at the two extremes of the stable mode 2 . For the hollow these are the following:

- Mode 1: A stable low current discharge $(I<8 \mu \mathrm{A})$

- Oscillation regime: $8 \mu \mathrm{A}<I<450 \mu \mathrm{A}$

- Mode 2: A stable higher current discharge $(450 \mu \mathrm{A}<$ $I<4 \mathrm{~mA}$ )

The voltage value across the electrode gap $\left(V_{\mathrm{GAP}}\right)$ is determined by measuring the voltage applied to the cathode $\left(V_{\mathrm{C}}\right)$ and the voltage dropped across the measurement resistor $\left(V_{\mathrm{MEAS}}\right)$, i.e. $V_{\mathrm{GAP}}=V_{\mathrm{C}}-V_{\mathrm{MEAS}}$.

\subsection{Electrical measurements of PP}

Mode 1 operation is inaccessible for the PP device and plasma breakdown occurs in the oscillating regime. Therefore, it is not possible to determine an exact $V_{\mathrm{BD}}$. Mode 2 operation does occur but it is restricted at the high current end for $I>\sim 1 \mathrm{~mA}$, and is pressure and gap dependent.

Figure 5 illustrates the $V-I$ behaviour of the PP device for a constant gap $(d=500 \mu \mathrm{m})$ and pressure range 11.8 Torr $<$ $p<39.1$ Torr. These data are plotted for $V_{\mathrm{GAP}}$ against current as it was not possible to measure a stable $V_{\mathrm{BD}}$. The

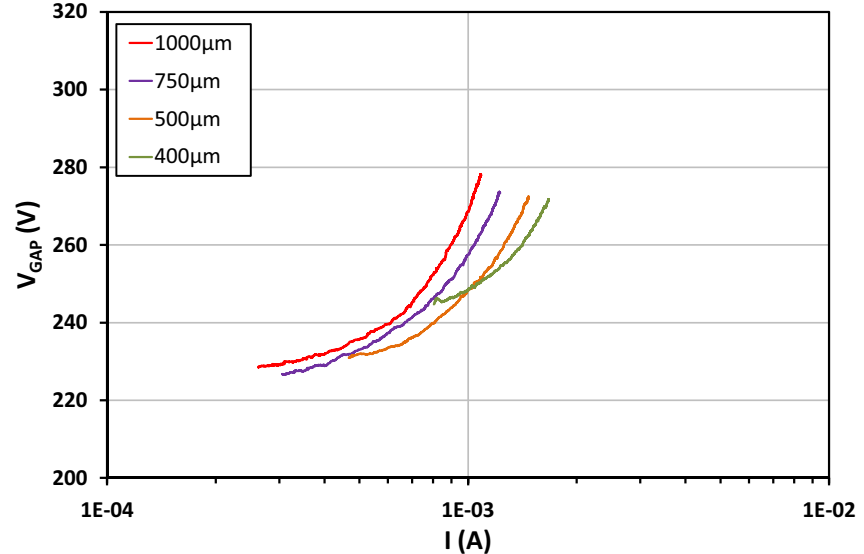

Figure 6. $V-I$ characteristics of mode 2 for a PP device where $p=14.1$ Torr.

observed current levels equate to maximum current densities, using nominal values of area, $\sim 300$ greater than the low pressure ( 5 mTorr) results reported by Petrović and Phelps ( $\sim 5 \mathrm{~cm}$ diameter anode) [42], suggesting our characteristics may be in the abnormal regime or near the glow-arc transition. Petrović and Phelps have clearly observed constriction of the discharges due to the proximity of the wall, thus affecting the accuracy of area estimates. However in our case, there is no proximate wall. We do not believe that glow-arc transition has occurred due to (i) stability/repeatability of the $V-I$ curves, (ii) the absence of electrode damage or temperature rise and (iii) pressure scaling, as detailed later. The current characteristics in figure 5 display positive differential resistance, except around $1.5 \mathrm{~mA}$ where some negative slopes are evident. For a given voltage, current increases with pressure. The upper limit of low current oscillation appears at $\sim 450 \mu \mathrm{A}$, irrespective of pressure, while the high current limit of stable $V-I$ curves, increases with pressure.

In figure 6 , the $V-I$ characteristics are shown for constant pressure (14.1 Torr) with variable gap, $400 \mu \mathrm{m}<d<1 \mathrm{~mm}$ and the curves display positive differential resistance across the current range. As the value of gap decreases, current increases for a fixed voltage, and the extent of the stable regime appears to reduce. For $d<400 \mu \mathrm{m}$, no discharge was observed, for $V_{\mathrm{GAP}}$ up to $600 \mathrm{~V}$.

\subsection{Electrical measurements of hollow cathode}

Electrical measurements were taken to determine the breakdown voltage VBD for the hollow device using the diagnostic circuit (figure 3). The values of VBD were determined from the turn-off point on the $V-I$ characteristic shown in figure 4 (and also figure 8).

Figure 7 shows $V_{\mathrm{BD}}$ versus $p d$ for fixed pressures of 14.1 Torr and 10 Torr for a range of $d$ and for fixed gaps of 250 and $50 \mu \mathrm{m}$ for a range of pressures. All data lie on the right side (high $p d$ ) of the Paschen minimum because the left side (low $p d$ ) is not accessible due to geometric restrictions and instabilities near $V_{\mathrm{BD}}$ at pressures lower than 10 Torr. With constant pressure, $V_{\mathrm{BD}}$ is almost constant, irrespective of $d$, and a self-adjusting path length, associated with $\mathrm{CHC}$ 


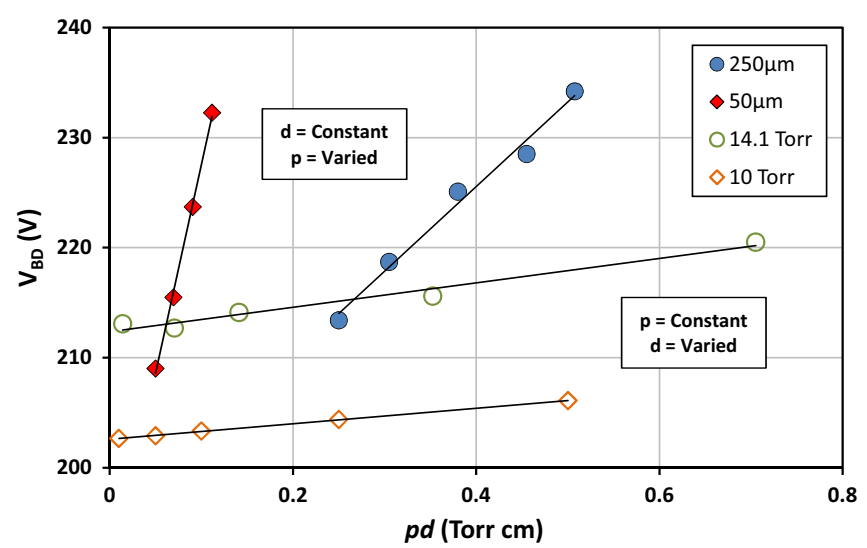

Figure 7. MHC device breakdown voltages for (i) varying pressure with constant gaps (50 $\mu \mathrm{m}$ and $250 \mu \mathrm{m}$, solid symbols) and (ii) constant pressure (10 Torr and 14.1 Torr) for variable gap.
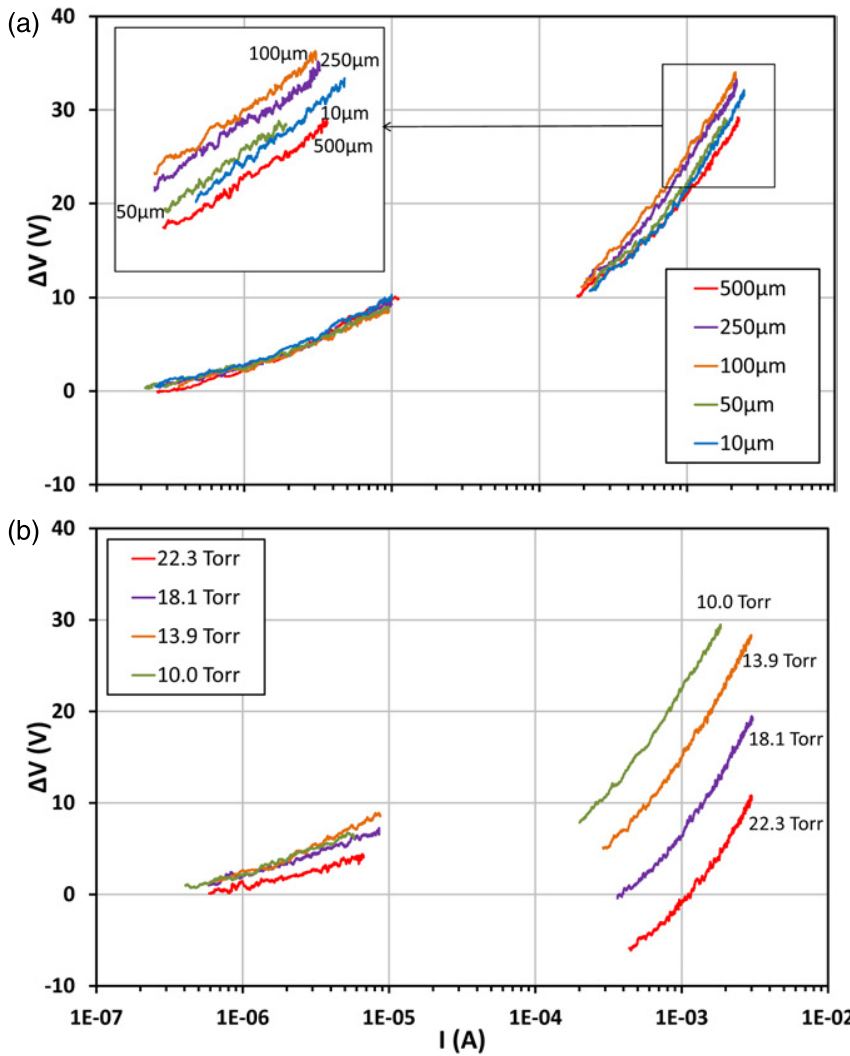

Figure 8. $V-I$ characteristics of MHC device for $(a)$ constant pressure (10 Torr) and variable gap from $10 \mu \mathrm{m}$ to $500 \mu \mathrm{m}$ and (b) constant $d(50 \mu \mathrm{m})$ for pressures in the range

10 Torr $<p<22.3$ Torr

geometry [37], may be involved. However, for constant $d$, a marked increased in $V_{\mathrm{BD}}$ is observed with increasing pressure.

$V-I$ characteristics were obtained for variable $d$ (fixed $p$ ) or variable pressure (fixed $d$ ) and are shown in figures $8(a)$ and $(b)$, respectively, as $\Delta V\left(=V_{\mathrm{GAP}}-V_{\mathrm{BD}}\right)$ against $I$. Here we note stable low current and high current regions, bounded by regions of oscillating $I$ and $V$, as indicated in figure 4 and denoted mode 1 and mode 2, respectively. For both sets of characteristics, the mode 1 upper limit is $\sim 10 \mu \mathrm{A}$ while mode 2 extends from $\sim 300 \mu \mathrm{A}$ to $4 \mathrm{~mA}$ and is dependent on

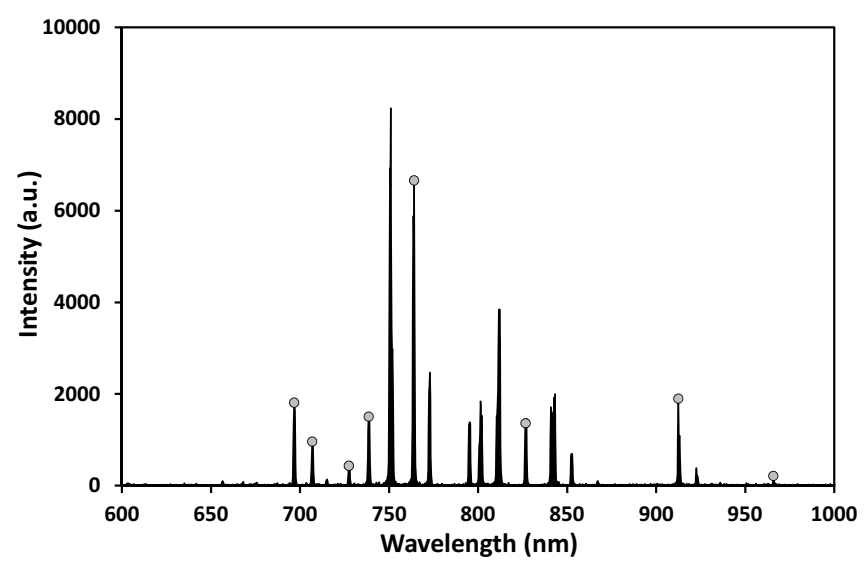

Figure 9. Optical emission spectrum of an argon discharge in the MHC device from fibre optic FO B. The lines indicated by circles are used to determine effective electron temperature.

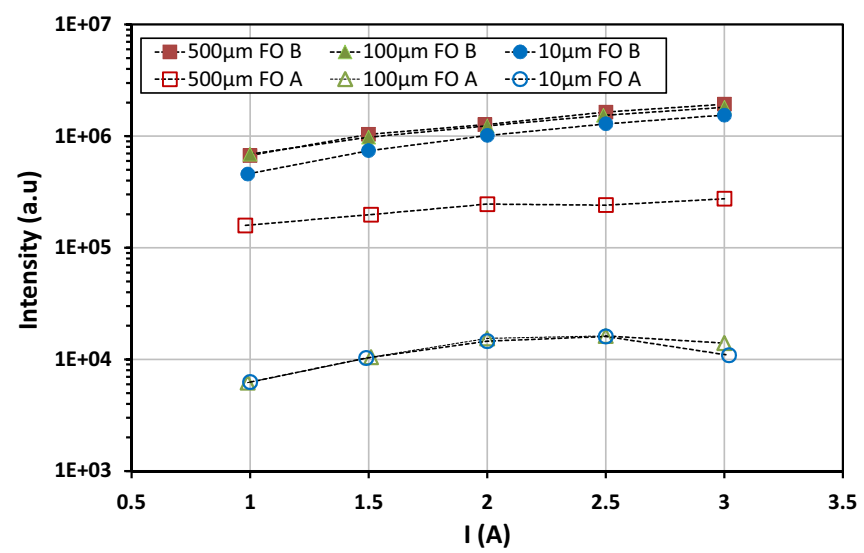

Figure 10. MHC total optical emission intensity against current for a range of gaps observed from fibre optics FO A and FO B.

pressure but shows little variation with gap. All curves exhibit positive slope.

\subsection{Optical emission spectroscopy}

Optical emission within the gap and the hollow was obtained in each current mode. Emission spectra (OES) were captured and used to estimate the effective electron temperature of the discharge. Figure 9 shows a typical spectrum of an argon discharge in our hollow cathode device, obtained via the rear fibre optic (FO B).

Figure 10 shows the total intensities from integrated hollow cathode device spectra versus current for a range of gaps ( $d=10 \mu \mathrm{m}, 100 \mu \mathrm{m}$ and $500 \mu \mathrm{m})$. Emission was captured at FO A (open symbols) and FO B (closed symbols) (see figure 2). For all three gaps, the total intensity measured at FO B, which collects photons from the front anode face and cathode tube interior, shows intensity rising with increasing current or $d$. Radial emission from the side of the gap, measured at FO A, is lower than at FO B by almost an order of magnitude for $d=500 \mu \mathrm{m}$ and by two orders of magnitude for $d=10 \mu \mathrm{m}$ and $100 \mu \mathrm{m}$. For $d=500 \mu \mathrm{m}$, FO A emission again rises with increasing current; however, for $d=10 \mu \mathrm{m}$ and $100 \mu \mathrm{m}$, the rise only extends to $I=2.5 \mathrm{~mA}$, above which a decrease 


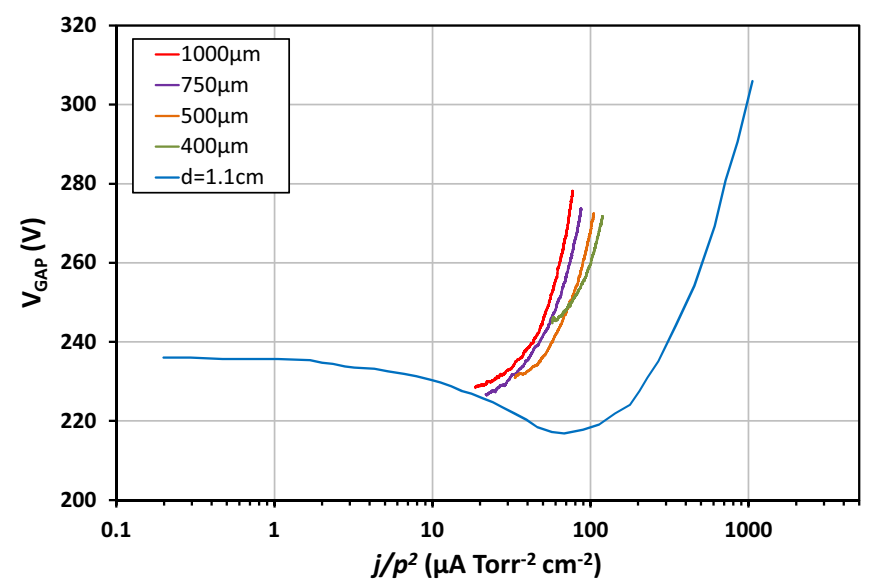

Figure 11. PP $j / p^{2}$ against $V_{\mathrm{GAP}}$ scaling characteristic, for several gaps at 14.1 Torr. The discharges are operating in mode 2 , where low current instabilities prevented measurement of $V_{\mathrm{BD}}$. The $1.1 \mathrm{~cm}$ gap data from Petrović et al [33] is also shown as a solid blue line for comparison.

is observed. This decrease may be evidence that at the smaller gaps, the discharge extends further into the hollow cathode as the current is increased, thus reducing radial emission collected at FO A.

\section{Discussion}

In recent years there has been a drive to reduce plasma dimensions to the microscale with many of the device structures based on hollow cathode geometries, typically a MDM sandwich structure. Scaling characteristics ( $p d, E / N$ and $j / p^{2}$ ) of dc PP plasmas on a macroscale are well known and are frequently invoked to model the behaviour of smaller devices [7] and although the low pressure/large scale hollow cathode is well understood [37] there has been little or no attempt to investigate the geometric scaling dependence of these structures.

\subsection{Electrical characteristics of $P P$}

PP structures have been characterized in depth for gaps of $1 \mathrm{~mm}$ and larger $[28,33,42,43]$ but by varying $p$ rather than $d$. In our previous work, we sought to obtain gap-dependent data for discrete gap values down to $20 \mu \mathrm{m}[13,29,33]$. In this work, we achieved a gap adjustment capability of $\pm 10 \mu \mathrm{m}$ but for PP, at a similar pressure range as our hollow cathode device, no operation below $400 \mu \mathrm{m}$ was possible and reliable $V_{\mathrm{BD}}$ values could not be obtained. We [33] and others [43] have observed $j / p^{2}$ scaling to hold for PP discharges. Figure 11 shows the scaling of $j / p^{2}$ with $V_{\mathrm{GAP}}$ for our present PP device, assuming the area of the discharge covers the entire cathode area (=anode area). For comparison we also plot data (solid blue line) from Marić et al [43] and Petrović et al [33], for a $1.1 \mathrm{~cm}$ gap, $5.4 \mathrm{~cm}$ diameter discharge operating at a value of $p d=0.5$ Torr $\mathrm{cm}$ in argon. A shift in data, similar to that observed in our previous study [33], is immediately apparent and may indicate reduced discharge area, i.e. constriction of the discharge. For all PP
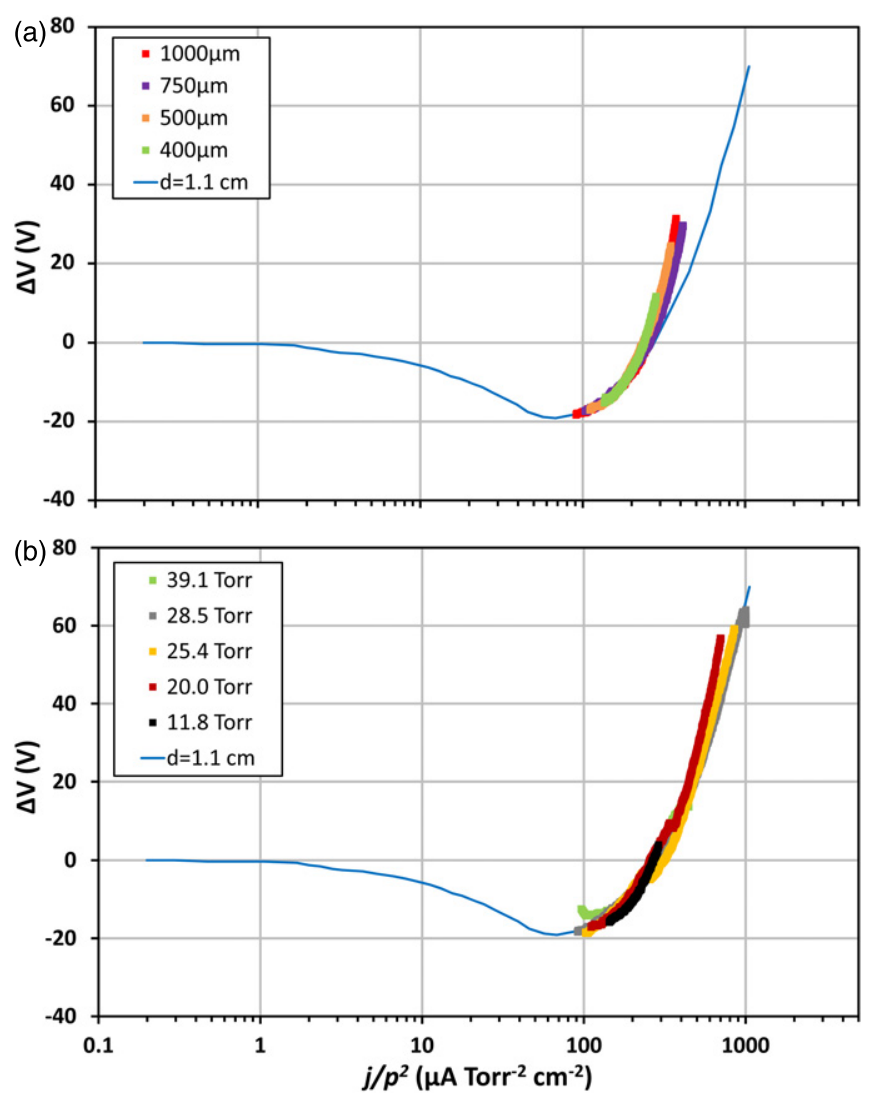

Figure 12. PP $\Delta V$ against $j / p^{2}$ scaling characteristic for $(a)$ variable gap at 14.1 Torr and $(b)$ variable pressure at $d=500 \mu \mathrm{m}$. Values of $V_{\mathrm{BD}}$ and effective discharge area are chosen to force plots to fit the large area data (blue line).

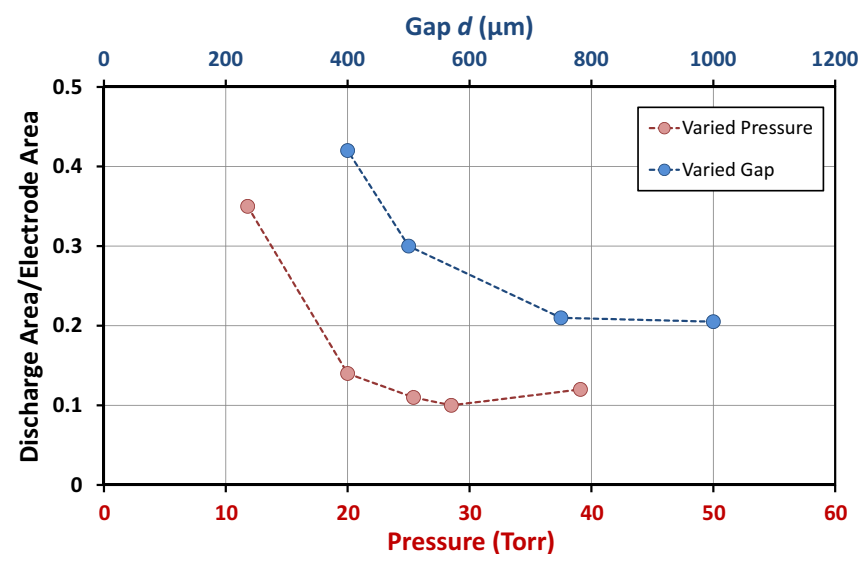

Figure 13. PP effective discharge area variation with $d(p=14.1$ Torr $)$ and $p(d=500 \mu \mathrm{m})$.

measurements, the slope of the $V-I$ gives differential plasma resistances ranging from $30 \mathrm{k} \Omega<R_{\text {PLASMA }}<65 \mathrm{k} \Omega$.

By calculating the current density for each data set using an effective (constricted) area value and an assumed value of $V_{\mathrm{BD}}$, we can force the plots of $\Delta V$ against $j / p^{2}$ to overlay the original large area $(1.1 \mathrm{~cm})$ data [33], figures $12(a)$ and $(b)$. The resultant effective area ratios are given in figure 13 against $d$ (fixed $p$ ) and $p$ (fixed $d$ ). For constant pressure (from figure 12(a)), the discharge areas decrease with increasing gap, from $\sim 0.4 A_{\text {CATHODE }}$ at 
$d=400 \mu \mathrm{m}$ to $\sim 0.2 A_{\mathrm{CATHODE}}$ at $d=1 \mathrm{~mm}$ while breakdown voltages decrease monotonically from 260 to $245 \mathrm{~V}$. There are noticeable minima at $p \sim 27$ Torr in both $V_{\mathrm{BD}}$ and discharge area for the constant gap (figure $12(b)$ ) data set; here the discharge area is $\sim 0.1 A_{\mathrm{CATHODE}}$ and $V_{\mathrm{BD}}=247 \mathrm{~V}$.

The $V_{\mathrm{BD}}$ behaviour is indicative of a Paschen minimum. Diffusion losses can be expected to lead to a non-uniform radial plasma density profile. The effective reduction in plasma area reflects that fraction of the profile that can be considered the low density edge of the plasma. The extent of this edge is expected to increase with increasing $d$ from radial diffusion considerations. However, for increasing pressure, we would expect less diffusion, hence a greater effective area, in contrast to observations.

\subsection{Electrical characteristics of hollow cathode}

The comparison of breakdown voltages, figure 7 , for variable $d$ at constant $p$ and vice versa indicates separate dependences on gap and pressure rather than on $p d$. However, for CHC devices, the geometrical constraints of Paschen breakdown $(p d)$ are generally relaxed, since the optimal plasma dimension for ignition is not restricted to the gap and long path breakdown can occur between the anode and some variable location within the hollow cavity [37]. We were unable to determine breakdown voltages for the PP case, in this work, however, we have previously shown [33] $\mathrm{Ar}(\mathrm{dc})$ breakdown voltages at $p d$ (min) of 0.6 Torr $\mathrm{cm}$ to 1.2 Torr $\mathrm{cm}$, for small gaps $(100 \mu \mathrm{m})$. Hence for an average of 0.9 Torr $\mathrm{cm}$, this implies a breakdown position sited between 100 and $900 \mu \mathrm{m}$ inside the cathode. The possibility of a self-adjusting path length is indicated by a near-horizontal Paschen-like characteristic at fixed pressure. However, for fixed $d$ and variable pressure, self-adjustment of the path length is insufficient to explain the rise in observed breakdown voltage. Given the very small gaps, we also considered the possibility of constant $p d$ breakdown arising due to enhanced fields between fixed locations on the electrodes even as the nominal gap value is varied, e.g. due to some radial feature such as the cathode edge. A new diagonal dimension, $\delta$, was considered, where $\delta^{2}=d^{2}+\varphi^{2}$ and $\varphi$ is the radial separation of arbitrary anode and cathode features. By varying $\varphi$ and re-plotting $V_{\mathrm{BD}}$ against $p \delta$, from figure 7, we obtain a set of characteristics of similar slopes using a value for $\varphi$ of $600 \mu \mathrm{m}$ (see figure 14). This is similar to standard Paschen behaviour, i.e. the right-hand side of a Paschen curve where the dimension $\delta$ is substituted for the nominal gap value, $d$. This value of $\varphi$ is the approximate radial distance between the cathode inner diameter and the anode diameter, and it may well be that the insulating cathode support suppresses the local electric field at the cathode outer edge.

The voltage-current characteristics $(\Delta V-I)$ indicate two current modes, low and high, separated by an oscillatory regime. In PP devices this oscillatory mode is indicative of the transition from Townsend to glow discharge mode. The discharge in mode 2 has a differential resistance (from the $V-I$ characteristics) of $5 \mathrm{k} \Omega<R_{\text {PLASMA }}<15 \mathrm{k} \Omega$, a factor of about 5 less than $R_{\text {PLASMA }}$ for mode 2 operation in PP geometry.

The standard current density-pressure relationship for PP is shown in figure 15 where $\Delta V$ is constant at low $j / p^{2}$ [28]

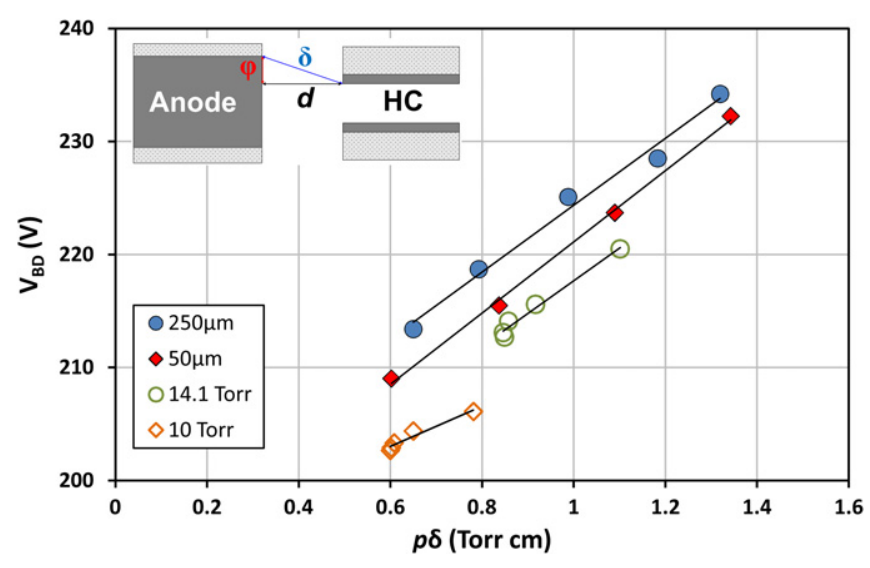

Figure 14. Breakdown voltages for hollow cathode with $\delta$ correction.

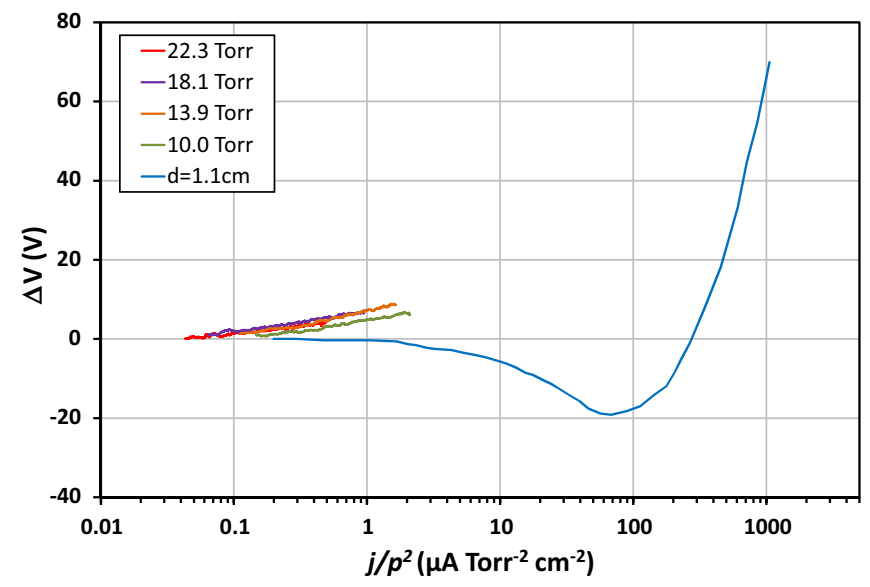

Figure 15. $j / p^{2}$ scaling for the MHC device mode 1 where $d=50 \mu \mathrm{m}$ assuming entire cathode face area is the discharge area. The blue line shows scaling for a conventional PP device [33].

and we observe similar behaviour at low current, where $j$ is calculated assuming the discharge area covers entire cathode face. Here $\Delta V$ rises slightly with $j / p^{2}$ and almost overlaps for all pressures. Similar behaviour is observed for $d=250 \mu \mathrm{m}$ and therefore $j / p^{2}$ scaling appears to hold for low currents but differs in slope (differential resistance $\sim 1 \mathrm{M} \Omega$ ) compared with that reported by Petrović et al [33] for larger PP devices. This suggests that mode 1 is operating in the Townsend regime. However, it is possible that the discharge breakdown occurs within the hollow cathode, given the possibility of a self-adjusting path length, mentioned above. In this case, the discharge cross-sectional area may be greatly constricted and much less than the nominal value used for $j$ allowing the characteristics to be arbitrarily shifted to any current density. However, for current densities associated with normal or abnormal mode operation, extremely restricted discharge dimensions would be required (i.e. diameter $<4 \mu \mathrm{m}$ ).

The high current characteristics are indicative of either an abnormal glow discharge (AGD) or high pressure hollow cathode operation (HPHC), since both display a positive differential resistance. In conventional low pressure devices, hollow cathode mode is characterized by ionization predominantly in the bulk plasma region with nearly all ions 


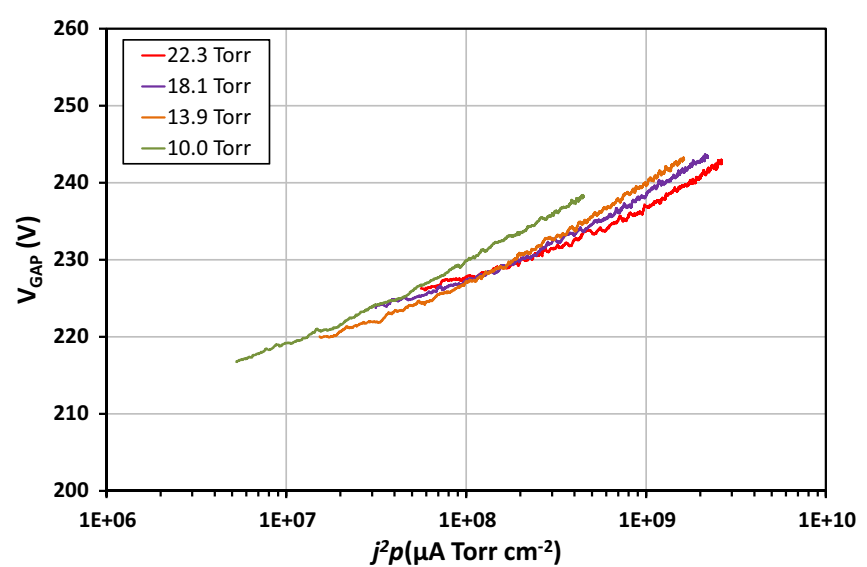

Figure 16. $V_{\mathrm{GAP}}$ against $j^{2} p$ scaling characteristic for the MHC device in mode 2 where $d=50 \mu \mathrm{m}$ and discharge area is assumed equal to the cathode face area.

reaching the cathode whereas AGD ionization occurs both in sheath and bulk but with less ion coupling between plasma and cathode [29]. At high pressure, Li et al [39] observes AGD mode as an annulus close to the cathode whereas in HPHC mode, the plasma extends uniformly across the diameter of the hollow. We observe a current density-pressure scaling in high current mode which follows a new relationship, namely $j^{2} p$ rather than $j / p^{2}$, figure 16. Again $j$ is calculated assuming a discharge area equal to the cathode face area. This is similar to the scaling relationship, $j=k L^{-5 / 2} p^{-1 / 2}$, from the analytical model of CHCs by Arslanbekov et al [37]. We see very good overlap of the data sets for $V-I$ data shown in figure $8(b)$ for a range of pressures for $d=50 \mu \mathrm{m}$ and similar trends hold for all gap and pressure ranges measured. The evidence of $j^{2} p$ scaling suggests HPHC rather than AGD mode operation.

Recent studies by Marić et al [38] for a single pressure and gap (3.5 Torr) show three distinct modes: (i) a low current $(<5 \mu \mathrm{A})$ Townsend-like discharge regime with negative differential resistance located in the gap, (ii) a normal glow-like discharge at intermediate currents $(15-200 \mu \mathrm{A})$ located both inside and outside the cavity and (iii) a high current hollow cathode (i.e. HPHC) mode ( $>200 \mu \mathrm{A})$ which is characterized by a clear increase in optical emission intensity, uniform across the cavity, and a drop in discharge voltage. Between modes (i) and (ii) free-running oscillations were observed but the transition from normal to hollow cathode (HPHC) is described as gradual. $V-I$ characteristics reported by Li et al [39] show only AGD mode followed directly by a high current HPHC mode when the plasma emission fills the tube. In this case no oscillations are reported. They also show a sheath width dependence on $j p^{0.5}$, equivalent to $j^{2} p$, in HPHC mode. Marić et al [38] and Li et al [39] operate at $p D$ values of $\sim 1$ Torr $\mathrm{cm}$ and 0.6-1.5 Torr $\mathrm{cm}$, respectively, compared with 2-7 Torr $\mathrm{cm}$ in this work and at $p d$ values of 1.6 Torr $\mathrm{cm}$ and 6 to 15 Torr $\mathrm{cm}$, respectively, compared with the range 0.01 to 4 Torr $\mathrm{cm}$ used here. Li et al [39], however, operate at lower current densities.

Three distinct $V-I$ operating modes are observed with MDM MHC devices [44]. Following breakdown there is a low current mode which is interpreted to be the Townsend discharge [45]. A second region with negatively differential resistivity

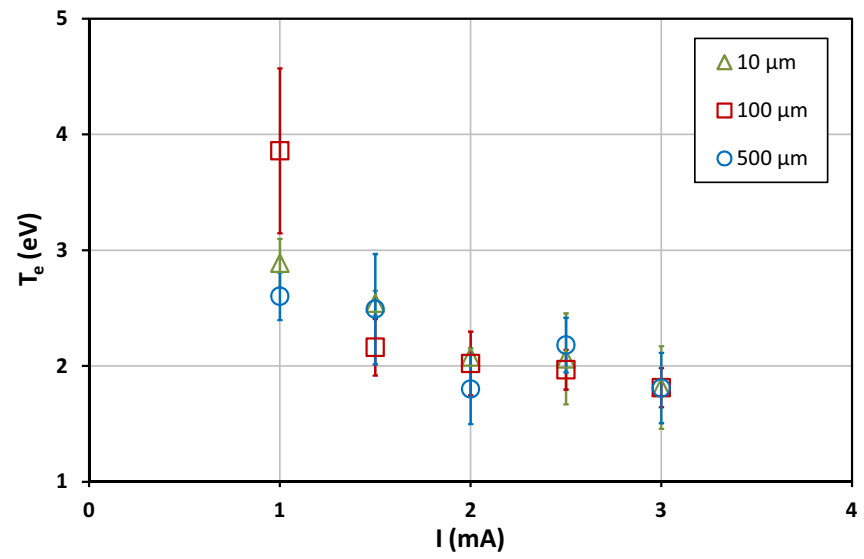

Figure 17. MHC device effective electron temperature determined from the TeM4 CR model using emission line intensity ratios measured in mode 2 at 14.1 Torr.

characteristics is attributed to the onset of the classical HCE. However, more recent reports $[20,46]$ have shown that these electrons do not possess enough energy to create multiple ionizations. Other work by Aubert et al has characterized this region to be a self-pulsing regime [41]. Schoenbach et al [45] also observe, for a $200 \mu \mathrm{m}$ diameter MHC ( $p D \sim 5$ Torr $\mathrm{cm}$ ), an annular emission structure in the low current resistive mode but beyond the transition to high current/low voltage, the plasma fills the cavity. Spectral imaging by Lazzaroni et al [47] also show an annular structure for $\mathrm{Ar}^{+}$ions $(p D=4$ Torr $\mathrm{cm})$ thought to be located at the sheath edge and which moves towards the cathode as pressure increases, i.e. sheath thickness decreases. Simulations by Kushner [40], for a MHC device ( $D=100 \mu \mathrm{m}, p D=\sim 2.5$ Torr $\mathrm{cm}$ ), show thin sheaths ( $s / D \sim 10 \%)$, AGD mode operation and ionization occurring mainly within or at the edge of the sheath. The plasma density $\left(>10^{14} \mathrm{~cm}^{-3}\right)$ peaks in the sheath near the cathode rim rather than within the hollow, due to the high electric field at the edge and gas heating/rarefaction dominates the scaling of characteristics. Kim et al [24] also show MHC ionization occurring in the centre of the cavity at low pressures ( $D=100 \mu \mathrm{m}, p D=0.1$ Torr $\mathrm{cm}$ ) but as pressure is increased $(p D=3$ Torr $\mathrm{cm})$ the ionization is pushed away from the centre and also towards the mouth of the cavity. These high pressure simulations represent similar values of $p D$ to those used in this work and with $p d \cong p D$, they overlap with our $p d$ values at the high end. Our observed $j^{2} p$ scaling suggests HPHC mode operation, i.e. the plasma is likely to exist inside the cavity with radial uniformity, unlike the situations predicted by both Kushner [40] and Kim et al [24].

\subsection{Effective electron temperature}

Figure 17 shows the effective electron temperature $\left(T_{\mathrm{e}}\right)$ determined from a balance equation solver (TeM4), which requires the input of measured spectral line intensities. The solver is the numerical implementation of a collisionalradiative $(\mathrm{CR})$ model $[8,48]$, which considers transitions from the $4 p$ argon levels (table 1). The main model assumption is that the $4 p$ levels are populated by electron-induced excitation from ground and from the metastable levels. 
Table 1. Selected $4 p$ argon levels and corresponding wavelengths.

\begin{tabular}{ll}
\hline $\begin{array}{l}\text { Level } \\
\text { (Paschen notation) }\end{array}$ & $\begin{array}{l}\text { Wavelength } \\
(\mathrm{nm})\end{array}$ \\
\hline $2 \mathrm{p}_{2}$ & 696.5430 \\
& 727.2935 \\
$2 \mathrm{p}_{3}$ & 826.4521 \\
& 706.7217 \\
$2 \mathrm{p}_{6}$ & 738.3980 \\
& 763.5105 \\
$2 \mathrm{p}_{10}$ & 992.4498 \\
& 912.2967 \\
\hline
\end{tabular}

The transitions considered here correspond to the three $2 \mathrm{p}_{2}$ lines, the two $2 p_{3}$ lines, one $2 p_{6}$ line (because in our case the $992.4498 \mathrm{~nm}$ line intensity was too low) and the two $2 \mathrm{p}_{10}$ lines. However, the solver requires the input of only one line intensity per level. This provided the opportunity to verify the stability of the model and its robustness to experimental line intensity fluctuations. Therefore, using different combinations of line intensity, the electron temperature at each microplasma condition could be calculated 12 times $(3 \times 2 \times 1 \times 2)$. Hence, the data points in figure 17 represent the average of 12 computations and the error bars are the corresponding standard deviations. It has to be noted that in two instances the solver was unable to determine the electron temperature for all 12 combinations of line intensities and in only 6 of the 12 combinations a solution was found. The data points that correspond to these two cases are therefore the average of only 6 computations. In figure 17 the effective temperature drops from about 3 to $2 \mathrm{eV}$ with increasing current for all gaps. There are few published measurements in hollow cathode or MHC discharges of electron temperature [26,49,50]. Effective temperatures range from 0.5 to $5 \mathrm{eV}$ and are reported to rise $[49,50]$, or remain constant [26] with discharge current (or power). There are no measured hollow cathode EEDFs in the literature; they have, however, been simulated or modelled [7, 24, 26, 35]. The resultant EEDFs are usually nonMaxwellian, with slow and fast electron populations, noted by Arslanbekov et al [37] and very often show a marked depletion above the excitation threshold ( $\sim 11 \mathrm{eV}$ in argon).

\subsection{Sheath thickness and number density}

Radial sheath models (see figure 18) were derived to determine the hollow cathode sheath thickness, $s$. Both non-ionizing and ionizing sheaths were examined by considering the analysis of Lieberman and Lichtenberg [51], Martínez and Amare [52] and the proposed sheath models of Lazzaroni et al [47].

4.4.1. Non-ionizing sheath thickness. For a non-ionizing sheath, secondary electrons emitted from the surface of the cathode at $r=R$ are accelerated by the electric field across the sheath which is significantly thinner than the ionization mean free path, i.e. $\left(s<\lambda_{\text {iz }}\right)$. Thus most ionization occurs within the bulk plasma. To determine the sheath thickness, we used a high voltage sheath model [51] where the mobility $\mu_{\mathrm{i}}$

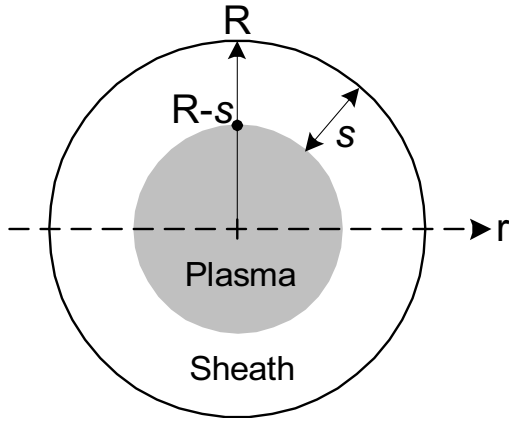

Figure 18. Schematic of the cylindrical hollow cathode structure showing the internal cathode radius $(R)$, sheath thickness $(s)$ and the sheath edge at $r=R-s$.

is a function of velocity and constant ion-neutral mean free path $\lambda_{\mathrm{i}}$ :

$$
\mu_{\mathrm{i}}=\frac{2 e \lambda_{\mathrm{i}}}{\pi m_{\mathrm{i}} u_{\mathrm{i}}} \quad \text { and } \quad u_{\mathrm{i}}=\mu_{\mathrm{i}} E .
$$

Lazzaroni et al [47] developed a relationship for the electric field $E(r)$ and thus $V_{\mathrm{d}}$ for cylindrical geometry in terms of cathode dimensions $R$ and $L$, secondary electron coefficient $\gamma$, measured current and $\lambda_{\mathrm{i}}$. They assume (i) $\mu_{\mathrm{i}}$ is independent of $r$ because $\lambda_{i}$ is constant and (ii) the current density at the cathode surface is the measured current density $J_{\text {im }}$, because there is no current source within the sheath. By integrating Gauss's equation, they obtained the electric field. In our nomenclature

$$
E(r)=\left[\frac{J_{\mathrm{im}} R}{\varepsilon_{0}} \sqrt{\frac{\pi m_{\mathrm{i}}}{2 e \lambda_{\mathrm{i}}}}\left(1-\left(\frac{R-s}{r}\right)^{3 / 2}\right)\right]^{2 / 3} .
$$

Setting $B=\left(J_{\mathrm{im}} R / \varepsilon_{0}\right) \sqrt{\pi m_{\mathrm{i}} / 2 e \lambda_{\mathrm{i}}}$ and $a=R-s$, a further integration gives the sheath potential $V_{\mathrm{s}}$, assumed to be equal to the potential drop $(\sim 250 \mathrm{~V})$ across the gap $V_{\mathrm{GAP}}$.

$$
V_{\mathrm{s}}=B^{2 / 3} \int_{a}^{a+s}\left(1-\left(\frac{a}{r}\right)^{3 / 2}\right)^{2 / 3} \mathrm{~d} r .
$$

The integration gives a hypergeometric function:

$$
\begin{aligned}
\int_{a}^{a+s} & \left(1-\left(\frac{a}{x}\right)^{3 / 2}\right)^{2 / 3} \mathrm{~d} x \\
= & {\left[x^{2}{ }_{2} F_{1}\left(-\frac{2}{3},-\frac{2}{3} ; \frac{1}{3} ;\left(\frac{a}{x}\right)^{3 / 2}\right)\right]_{a}^{a+s} }
\end{aligned}
$$

from which, for a range of currents, values of $s$ are selected to satisfy equation (1). We have assumed a discharge length equal to the length of the hollow cathode, $L$.

The plot in figure 19 shows the variation of $s$ with current derived from the model, for a range of pressures. At the lower pressure limit ( $p=100$ Torr) the sheath occupies the entire radius $(R=900 \mu \mathrm{m})$ for $I=0.5 \mathrm{~mA}$. The sheath thickness decreases somewhat with increasing pressure but more markedly with current. The narrowest sheaths, $s \sim 350 \mu \mathrm{m}$, occur at the upper pressure and current limits ( $p=\sim 22$ Torr, $I=3 \mathrm{~mA}$ ). This sheath thickness is, however, several times the ionization mean free path in argon, and is strong evidence that a non-ionizing sheath model is not appropriate for the hollow cathode discharge. 


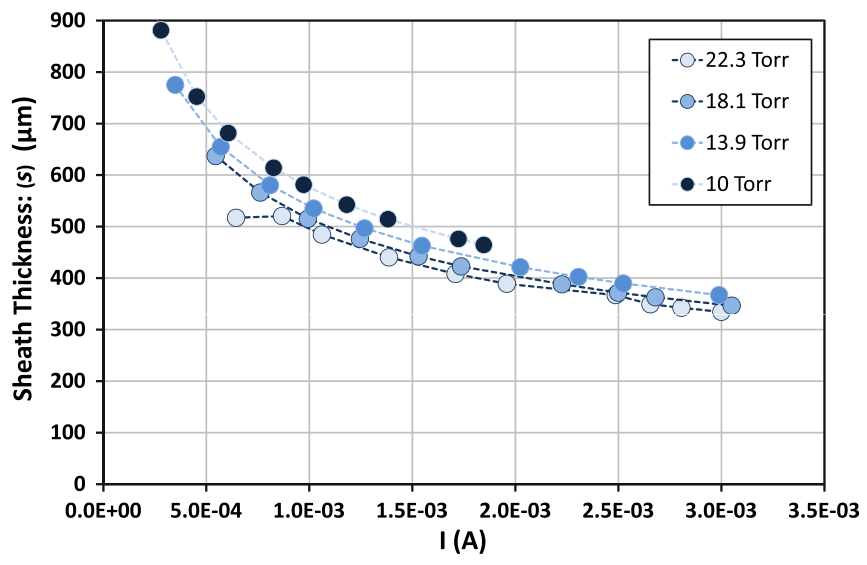

Figure 19. MHC sheath thickness against current for a range of pressures, derived from the non-ionizing sheath model.

4.4.2. Ionizing sheath thickness. In the case of an ionizing sheath, $s>\lambda_{\mathrm{iz}}$ and the secondary electrons undergo sufficient collisions within the sheath to cause significant multiplication. Equal creation of electron-ion pairs leads to additional electron, $I_{\mathrm{es}}$, and ion, $I_{\mathrm{is}}$, currents, respectively:

$$
\begin{gathered}
I_{\mathrm{is}}=I_{\mathrm{es}} \\
I_{\mathrm{es}}=I_{\mathrm{e}}(R-s)-I_{\mathrm{e}}(R) \\
I_{\mathrm{is}}=I_{\mathrm{i}}(R)-I_{\mathrm{i}}(R-s) .
\end{gathered}
$$

Also

$$
I_{\mathrm{e}}(R)=\gamma I_{\mathrm{i}}(R) .
$$

Defining an ion multiplication factor, $M$ :

$$
I_{\mathrm{i}}(R)=M I_{\mathrm{i}}(R-s)
$$

we note that an ionizing sheath requires $M>2$ [47] and $M$ is very large when ionization in the sheath dominates. The corresponding relationship for electron multiplication is

$$
I_{\mathrm{e}}(R-s)=\left(\frac{M-1}{\gamma M}+1\right) I_{\mathrm{e}}(R) .
$$

Eliminating $I_{\mathrm{es}}$ and $I_{\mathrm{is}}$ from equations (2) to (4) and converting to fluxes [47] gives

$R \Gamma_{\mathrm{i}}(R)-(R-s) \Gamma_{\mathrm{i}}(R-s)=(R-s) \Gamma_{\mathrm{e}}(R-s)-R \Gamma_{\mathrm{e}}(R)$.

The relationship between $\Gamma_{\mathrm{e}}$ and the first Townsend coefficient $\alpha\left(=1 / \lambda_{\mathrm{iz}}\right)$ for one-dimensional cylindrical geometry can be written as [51]

$$
\nabla \Gamma_{\mathrm{e}}=\alpha(r) \Gamma_{\mathrm{e}}
$$

which can be solved between $R-s$ and $R$ to give

$$
\Gamma_{\mathrm{e}}(R-s)=\Gamma_{\mathrm{e}}(R)\left[\frac{R}{R-s} \exp \left(\int_{R-s}^{R} \alpha(r) \mathrm{d} r\right)\right] .
$$

Combining equations (5) to (8) gives

$$
\int_{R-s}^{R} \alpha(r) \mathrm{d} r=\ln \left(\frac{M-1}{\gamma M}+1\right) .
$$

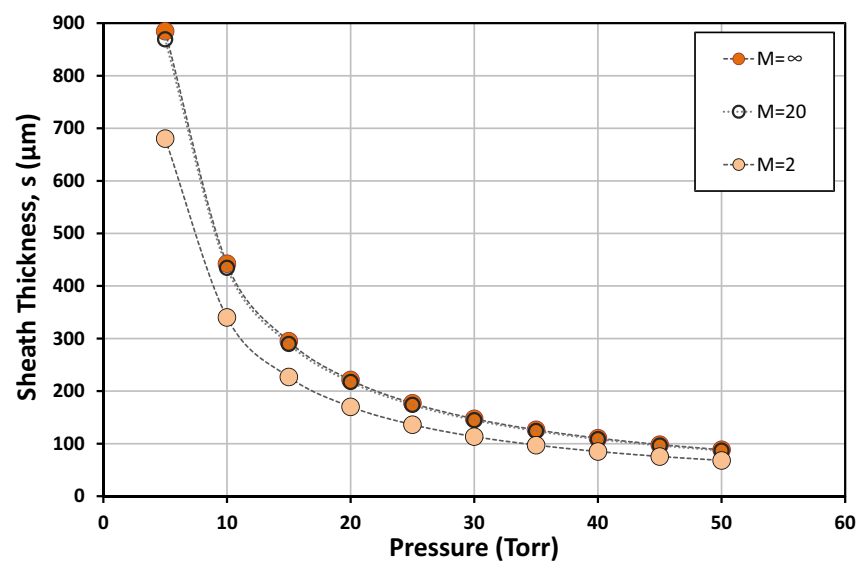

Figure 20. MHC sheath thickness derived from the ionizing sheath model for $R=900 \mu \mathrm{m}$. The sheath almost fills the cathode for $p<7$ Torr, indicating the lower discharge operating limit.

The coefficient $\alpha(r)$ is a function of pressure and electric field [53]. For our MHC pressure range and minimum estimated electric field from $E \sim V_{\mathrm{s}} / R(\sim 250 \mathrm{~V} / 9 \times$ $\left.10^{-4} \mathrm{~m}\right)$, the reduced field $E / n_{\mathrm{g}}$ is greater than $750 \mathrm{Td}$ $\left(\sim 265 \mathrm{~V} \mathrm{~cm}^{-1} \mathrm{Torr}^{-1}\right.$ at $\left.300 \mathrm{~K}\right)$. Using field-intensified ionization cross-section, $\alpha / n_{\mathrm{g}}$, versus $E / n_{\mathrm{g}}$, data [51,53], $\alpha / n_{\mathrm{g}}$ is roughly constant $\left(\sim 3 \times 10^{20} \mathrm{~m}^{2}\right)$ above our minimum $E / n_{\mathrm{g}}$ value. By integrating equation (9) between $R-s$ and $R$, the sheath thickness relationship was obtained

$$
s=\frac{1}{\alpha} \ln \left(\frac{M-1}{\gamma M}+1\right)
$$

and plotted in figure 20 for various pressures ( 5 Torr $\leqslant p \leqslant$ 50 Torr) and multiplication factors $(2 \leqslant M \leqslant \infty)$ using $\alpha$ and $\gamma$ values of $3.0 \times 10^{20} \mathrm{~m}^{2}$ and 0.07 , respectively. At pressures $<7$ Torr the sheath occupies almost the entire internal radius of the hollow cathode $(900 \mu \mathrm{m})$. This coincides with the lower discharge operating limit of about 5 Torr. For operating pressures (10 Torr to 40 Torr), $0.5>s / R>0.1$, which is at least 4 mean free paths for ionization and is strong evidence that the hollow cathode mode observed here operates with ionizing sheaths.

4.4.3. Plasma density. The solution of the diffusion equation is relatively complex for an ionizing sheath because electronion pair creation varies markedly along the radius; it rises from the cathode to the sheath edge then decays in the bulk plasma. This results in a non-uniform ionization (source) term $G(r)$, which peaks at the bulk plasma/sheath boundary, and makes analytical solution of the diffusion equation cumbersome. We have, however, developed a finite difference technique which assumes $G(r)$ decreases exponentially inwards from the bulk/sheath boundary to solve the diffusion equation within the bulk plasma and thus determine the density profile. $G(r)$ decreases from a peak value $G_{0}$ at the sheath edge with a characteristic length $\lambda_{\mathrm{pl}}$ in the bulk plasma

$$
G(r)=G_{0} \exp \left(-\frac{R-s-r}{\lambda_{\mathrm{pl}}}\right) .
$$


We calculate $\lambda_{\mathrm{pl}}$ from $E_{\mathrm{pl}}$, the average kinetic energy of electrons arriving at the bulk plasma. It is reasonable to assume that $E_{\mathrm{pl}} \sim E_{\mathrm{sh}} / 2$, half the average electron kinetic energy in the sheath. Considering an 'ideal' electron which undergoes $n_{\text {coll }}$ identical collisions and gains the same energy $E_{\text {sh }}$ before each collision, then

$$
\sigma_{\mathrm{sh}} E_{\mathrm{sh}}=\frac{e V_{\mathrm{s}}}{s n_{\mathrm{g}}} .
$$

Here $\sigma_{\mathrm{sh}}$ is the cross-section at $E_{\mathrm{sh}}$. For $p=14.1$ Torr, $I=3 \mathrm{~mA}, s=300 \mu \mathrm{m}$ and $T_{\mathrm{e}}=2 \mathrm{eV}, E_{\mathrm{sh}} \sim 60 \mathrm{eV}$, $\sigma_{\mathrm{sh}} \sim 2.7 \times 10^{-20} \mathrm{~m}^{2}, n_{\text {coll }} \sim 4.3$ and $\lambda_{\text {sh }} \sim 71 \mu \mathrm{m}$ for the sheath and $E_{\mathrm{pl}} \sim 30 \mathrm{eV}, \sigma_{\mathrm{pl}} \sim 1.8 \times 10^{-20} \mathrm{~m}^{2}$ and $\lambda_{\mathrm{bp}} \sim 100 \mu \mathrm{m}$ in the bulk plasma. The sheath edge source term $G_{0}$ was calculated from the neutral gas density $n_{\mathrm{g}}, \sigma_{\mathrm{bp}}$ and electron flux $\Gamma_{\mathrm{e}}$ (determined from the measured current, the electron multiplication factor $\exp \left(n_{\text {coll }}\right)$ and an assumed value for the cathode secondary electron coefficient $\gamma$ ).

$$
G_{0}=n_{\mathrm{g}} \sigma_{\mathrm{pl}} \Gamma_{\mathrm{e}} .
$$

To determine the density profile, we use the standard steadystate ambipolar diffusion with coefficient $D_{\mathrm{a}}$ and assume no losses within the plasma

$$
-D_{\mathrm{a}} \nabla^{2} n=G(r)
$$

which in expanded form

$$
\frac{\mathrm{d}}{\mathrm{d} r}\left(r \frac{\mathrm{d} n}{\mathrm{~d} r}\right)=-\frac{r G(r)}{D_{\mathrm{a}}}
$$

may be rewritten as a finite difference equation:

$$
\begin{aligned}
& \frac{1}{\delta}\left(\left(\rho+\frac{\delta}{2}\right) \frac{\left(n_{\rho+\delta}-n_{\rho}\right)}{\delta}-\left(\rho-\frac{\delta}{2}\right) \frac{\left(n_{\rho}-n_{\rho-\delta}\right)}{\delta}\right) \\
& =-\frac{\rho G(\rho)}{D_{\mathrm{a}}}
\end{aligned}
$$

where $\rho$ is radial position, $\delta$ the step size and $n_{\rho}$ the number density at $r=\rho$. Solving for number density at each position gives

$n_{\rho}=\frac{1}{2}\left(n_{\rho+\delta}+n_{\rho-\delta}+\frac{\delta}{2 \rho}\left(n_{\rho+\delta}-n_{\rho-\delta}\right)+\frac{G(\rho) \delta^{2}}{D_{\mathrm{a}}}\right)$.

To determine the number density profile, the region between the plasma centre and cathode was divided into $90 \times 10 \mu \mathrm{m}$ steps. $G(\rho)$ was calculated from

$$
G(\rho)=G_{0} \exp \left(-\frac{\rho}{\lambda_{\mathrm{bp}}}\right)
$$

and an iteration routine was used to solve (11) for $n_{\rho}$, using $n_{\rho}=0$ at $r=R-s$ as a boundary condition.

The finite difference iteration routine was checked by comparison with a known analytical solution, i.e. the simpler case of a non-ionizing sheath [51, p 553, equation (14.4.6)]. The latter predicts a parabolic electron density profile with peak number density $n_{\mathrm{e} 0}$ related to the measured current $I_{\mathrm{dc}}$, the ambipolar diffusion coefficient and cathode length and given by

$$
n_{\mathrm{e} 0}=\frac{I_{\mathrm{dc}}}{4 \pi l e D_{\mathrm{a}}} .
$$

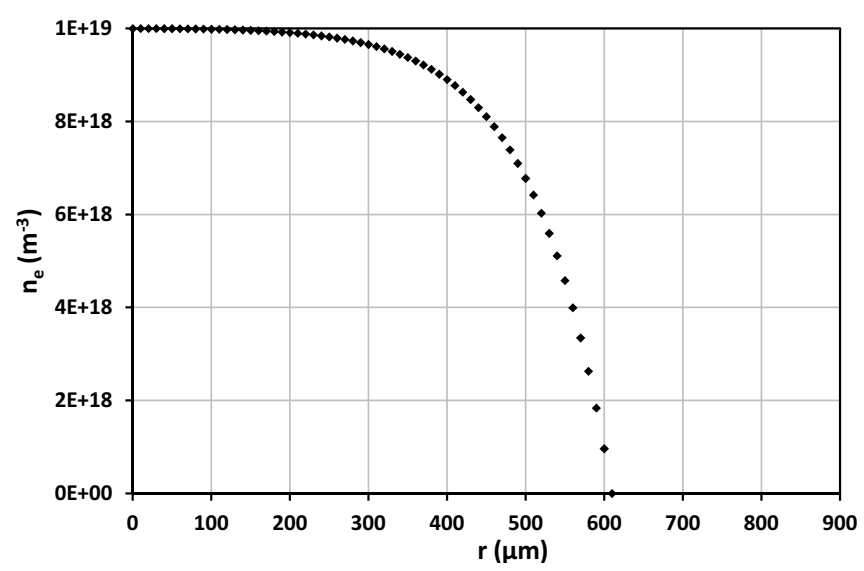

Figure 21. MHC plasma density profile determined from the diffusion model in the case of an ionizing sheath: $s=300 \mu \mathrm{m}$, $p=15$ Torr, $I=3 \mathrm{~mA}, T_{\mathrm{e}}=2 \mathrm{eV}$.

For the pressure, electron temperature and currents used above, $n_{\mathrm{e} 0} \sim 1.2 \times 10^{13} \mathrm{~cm}^{-3}$. The finite difference iteration routine gave the expected parabolic profile, the peak value of which was dependent on secondary electron coefficient The value of $\gamma$ was adjusted and the resultant peak density made to match the analytical result with a value of $\gamma=0.15$, which is realistic and hence provides confidence in the accuracy of the finite difference model.

Figure 21 shows the output of the diffusion model for our hollow cathode operating with an ionizing sheath; the number density has a flat topped domed profile, with an axial density of about $10^{13} \mathrm{~cm}^{-3}$. By considering measured currents, a realistic secondary electron coefficient, sheath multiplication factor and sheath arrival energies, the peak density $n_{\mathrm{EF}}$ of the fast electron beam at $r=R-s$ can be shown to be much lower than the axial density $n_{\mathrm{E}}: n_{\mathrm{EF}} / n_{\mathrm{E}}<\sim 10_{\rho}^{-4}$. This justifies our assumed boundary condition that $n_{\rho}=0$ at $r=R-s$.

For the sheath and diffusion models, it has been assumed that the discharge of length $l_{\text {plas }}$ longitudinally fills the cathode: $l_{\text {plas }}=L=10 \mathrm{~mm}$. In order to consider the case of shorter plasmas we estimate a lower limit of $l_{\text {plas }}$ for valid 1D radial modelling. Considering the plasma to be a cylinder radius $r$ length $l$ capped with a hemisphere. Two geometric criteria could be assumed: the ratio of cylinder to cap areas $\left(A_{\mathrm{CYL}}\right.$ and $\left.A_{\mathrm{CAP}}\right)$ or their respective volumes $\left(V_{\mathrm{CYL}}\right.$ and $\left.V_{\mathrm{CAP}}\right)$. For our geometry $A_{\mathrm{CYL}}=5 A_{\mathrm{CAP}}$ for $l=3 \mathrm{~mm}$, for $l=2 \mathrm{~mm}$. It is thus reasonable to assume that $2 \mathrm{D}$ effects are not important and 1D analysis is valid for plasmas longer than $\sim 2.5 \mathrm{~mm}$ in our geometry. Further, this geometrical criterion may be an overestimate if we consider the plasma production mechanisms. The higher values of $E / n$ across the radial sheath compared with those around the end cap will produce much greater ionization at the radial sheath edge.

The non-ionizing sheath thickness calculation (figure 19) is sensitive to current density and thus the assumed value of $l_{\text {plas }}$. Hence we consider the case of a 14 Torr discharge at its longitudinal limit $l_{\text {plas }},=L / 4=2.5 \mathrm{~mm}$ : at $1 \mathrm{~mA}$ the sheath thickness decreases from 560 to $\sim 300 \mu \mathrm{m}$ and at $3 \mathrm{~mA}$ it decreases from $360 \mu \mathrm{m}$ to $\sim 200 \mu \mathrm{m}$. The latter sheath thickness is $\sim 3 \lambda_{\mathrm{iz}}$, so ionizing sheaths pertain for all 
reasonable plasma lengths. For the ionizing sheath model, however, thickness is independent of current density and thus figure 20 is valid for all $l_{\text {plas }}$. Inspection of the diffusion analysis used to determine the number density profile (figure 21) shows the density to be inversely proportional to discharge length, but with an unaltered profile, i.e. the number density would again be a flat topped domed profile but with an axial density of about $4 \times 10^{13} \mathrm{~cm}^{3}$ for the limiting discharge length.

\section{Conclusion}

Parallel plate and hollow cathode microplasma structures were compared at high pressure with narrow anode-cathode gaps using a moveable anode arrangement with accurate spatial resolution. For $p d$ values between 0.01 and 4 Torr $\mathrm{cm}$, there is no obvious indication of Paschen-like breakdown behaviour if the nominal value of $d$ is used. However, a self-adjusting path length is possible with breakdown occurring between anode and a short distance $(<1 \mathrm{~mm})$ inside the cathode, as indicated by a near-horizontal Paschen-like characteristic at fixed pressure. However, for fixed $d$ and variable pressure, self-adjustment of the path length is insufficient to explain the rise in observed breakdown voltage. An additional effect due to enhanced fields between local sites on the two electrodes was shown to be feasible.

Current-voltage characteristics showed a low current mode, most likely a Townsend-like annular discharge extending from the anode to the cathode face and a short distance $(<1 \mathrm{~mm})$ into its interior surface determined by optimum $p d$ values. The high current mode shows evidence of high pressure hollow cathode operation since current-pressure scales as $j^{2} p$ rather than $j / p^{2}$. The longitudinal extent of this mode has not been established, however, for lengths between $0.25 L$ and $L$, analytical models show that ionization occurs predominantly within the sheath, with an ion multiplication factor $\sim 20$ at $p=15$ Torr, $I=3 \mathrm{~mA}$. Between 10 and 40 Torr, the estimated sheath thickness varied between $50 \%$ and $10 \%$ of the diameter, indicating a constriction of the axial plasma column as pressure is reduced and an extinction limit of $\sim 7$ Torr similar to that observed experimentally. For a discharge restricted to the cathode mouth, a transition between ionizing and non-ionizing sheath conditions remains a possibility. Numerical modelling suggests the number density exhibits a flat topped domed profile, with a peak axial density in the order of $4 \times 10^{13} \mathrm{~cm}^{-3}$ depending on the assumed value of discharge length. Electron temperature obtained from emission spectra, for all gap values, shows a dependence on current with $T_{\mathrm{e}}$ falling from $\sim 3$ to $2 \mathrm{eV}$ as the current is raised from 1 to $3 \mathrm{~mA}$ (14 Torr).

\section{References}

[1] Becker K H, Schoenbach K H and Eden J G 2006 J. Phys. D: Appl. Phys. 39 R55

[2] Foest R, Schmidt M and Becker K 2006 Int. J. Mass Spectrom. 24887

[3] Schoenbach K H, Moselhy M, Shi W and Bentley R 2003 J. Vac. Sci. Technol. 211260
[4] Mariotti D, Lindström H, Bose A C and Ostrikov K K 2008 Nanotechnology 19495302

[5] Boettner H, Waskoenig J, O'Connell D, Kim T L, Tchertchian P A, Winter J and Schulz-von der Gathen V 2010 J. Phys. D: Appl. Phys. 43124010

[6] Park S J, Chen J, Wagner C J, Ostrom N P, Liu C and Eden J G 2002 IEEE J. Sel. Top. Quantum Electron. 8387

[7] Petrov G M and Zhechev D 2002 Phys. Plasmas 91815

[8] Mariotti D, Shimizu Y, Sasaki T and Koshizaki N 2007 J. Appl. Phys. 101013307

[9] Pessoa R S, Sismanoglu B N, Amorim J, Maciel H S and Petriconi G 2007 Gas Discharges: Fundamentals and Applications vol 1 ed J Amorim (Kerala: Transworld Research Network) pp 175

[10] Iza F, Kim G J, Lee S M, Lee J K, Walsh J L, Zhang Y T and Kong M G 2008 Plasma Process. Polym. 5322

[11] McLaughlin J A and Maguire P D 2008 Diamond Relat. Mater. 17873

[12] Mariotti D, Maguire P, Mahony C M O and McLaughlin J 2004 Plasma Sources Sci. Technol. 13576

[13] Mariotti D, McLaughlin J A and Maguire P 2004 Plasma Sources Sci. Technol. 13207

[14] Tachibana K 2006 IEEJ Trans. Electr. Electron. Eng. 1145

[15] Schoenbach K H, Verhappen R, Tessnow T, Peterkin F E and Byszewski W W 1996 Appl. Phys. Lett. 6813

[16] Sankaran R M and Giapis K P 2001 Appl. Phys. Lett. 79593

[17] Frame J W, Wheeler D J, DeTemple T A and Eden J G 1997 Appl. Phys. Lett. 711165

[18] Park S J, Wagner C J, Herring C M and Eden J G 2000 Appl. Phys. Lett. 77199

[19] Park S J and Eden J G 2002 Appl. Phys. Lett. 814127

[20] Boeuf J P, Pitchford L C and Schoenbach K H 2005 Appl. Phys. Lett. 86071501

[21] Miclea M, Kunze K, Heitmann U, Florek S, Franzke J and Niemax K 2005 J. Phys. D: Appl. Phys. 381709

[22] Moselhy M, Petzenhauser I, Frank K and Schoenbach K H 2003 J. Phys. D: Appl. Phys. 362922

[23] Penache C, Miclea M, Bräuning-Demian A, Hohn O, Schössler S, Jahnke T, Niemax K and Schmidt-Böcking H 2002 Plasma Sources Sci. Technol. 11476

[24] Kim G J, Iza F and Lee J K 2006 J. Phys. D: Appl. Phys. 394386

[25] Mariotti D 2008 Appl. Phys. Lett. 92151505

[26] Penache M C $2002 P h D$ Thesis Universitat in Frankfurt

[27] Mariotti D and Sankaran R M 2010 J. Phys. D: Appl. Phys. 43323001

[28] Phelps A V 2001 Plasma Sources Sci. Technol. 10329

[29] Petrović Z Lj, Malovic G, Radmilovic-Radjenovic M, Puac N, Marić D, Maguire P and Mahony C 2006 Proc. MIEL 2006 IEEE ED-SSC (Belgrade, Serbia, 14-17 May) p 39

[30] Radmilovi -Radjenovi M, Lee J K, Iza F and Park G Y 2005 J. Phys. D: Appl. Phys. 38950

[31] Staack D, Farouk B, Gutsol A and Fridman A 2005 Plasma Sources Sci. Technol. 14700

[32] Staack D, Farouk B, Gutsol A and Fridman A 2008 Plasma Sources Sci. Technol. 17025013

[33] Petrović Z Lj, Škoro N, Marić D, Mahony C M O, Maguire P D, Radmilović-Radenović M and Malović G 2008 J. Phys. D: Appl. Phys. 41194002

[34] Little P F and Von Engel A 1954 Proc. R. Soc. Lond. A 224209

[35] Kolobov V I and Tsendin L D 1995 Plasma Sources Sci. Technol. 4551

[36] Pillow M E 1981 Spectrochim. Acta B 36821

[37] Arslanbekov R R, Kudryavtsev A A and Tobin R C 1998 Plasma Sources Sci. Technol. 7310

[38] Marić D, Škoro N, Malovi G, Petrović Z Lj, Mihailov V and Djulgerova R 2009 J. Phys.: Conf. Ser. 162012007 
[39] Shang L, Ji-Ting O and Feng H 2010 Chin. Phys. Lett. 27065201

[40] Kushner M J 2005 J. Phys. D: Appl. Phys. 381633

[41] Aubert X, Bauville G, Guillon J, Lacour B, Puech V and Rousseau A 2007 Plasma Sources Sci. Technol. 1623

[42] Petrović Z Lj and Phelps A V 1997 Phys. Rev. E 565920

[43] Marić D, Hartmann P, Malovic G, Donko Z and Petrović Z Lj 2003 J. Phys. D: Appl. Phys. 362639

[44] Shi W, Stark R H and Schoenbach K H 1999 IEEE Trans. Plasma Sci. 2716

[45] Schoenbach K H, El-Habachi A, Shi W and Ciocca M 1997 Plasma Sources Sci. Technol. 6468

[46] Gomes M P, Sismanoglu B N and Amorim J 2009 Braz. J. Phys. 3925
[47] Lazzaroni C, Chabert P, Rousseau A and Sadeghi N 2010 J. Phys. D: Appl. Phys. 43124008

[48] Mariotti D, Shimizu Y, Sasaki T and Koshizaki N 2006 Appl. Phys. Lett. 89201502

[49] Mahony C M O, Gans T, Graham W G, Maguire P D and Petrović Z Lj 2008 Appl. Phys. Lett. 93011501

[50] Maciel H S, Petraconi G and Pessoa R 2004 12th Int. Congress on Plasma Physics, Nice

[51] M Lieberman and Lichtenberg A 2005 Principles of Plasma Discharges and Materials Processing 2nd edn (New York: Wiley)

[52] Martínez J P and Amare J C 1998 J. Phys. D: Appl. Phys. 31312

[53] Maric D, Radmilovi-Radenovi M and Petrovic Z L 2005 Eur. Phys. J. D 35313 